\title{
THE UNIT OF SOCIAL ORGANIZATION IN A LARGE TOWN.'
}

A FACT obvious at the commencement of any study of the Social Organization of the town is that the large town is not a single social unit-that is to say, a social group possessing a single set of social institutions. As a person travels from one end of a large town to the other, or makes a circle round the outskirts of the town, he finds himself passing through a series of districts having much the same characteristics and possessing more or less similar institutions-e.g., churches, schools, swimming baths, post offices, clubs, and their consequent activities-debating societies, athletic clubs, social evenings, etc., etc. When he pursues the matter a little he finds that these districts or units are not distinct or separate, but are an involved tangle with only here and there apparent nuclei. The further he pursues his investigations, the more involved does this tangle become. In a consideration of this subject three points may be mentioned at the outset.

In the first place, the unit of the town's progression has not consisted of a complete social group with houses, streets, shopping thoroughfares, institutions, and open spaces complete and in an ordered relation. Instead the unit has been that of an individual house or a row of houses. These have been put up, generally speaking, without any relation to a district as a whole, and frequently without any definite intention of their ever being an integral part of any district. Further, this general spread of the town by individual houses has destroyed the unity and definiteness of the already existing village on the outskirts, which the town encounters, absorbs, transforms and strangles in its amorphous growth.

The second point is that there is at present no recognized standard of social organization for any district. We are only feeling our way in this direction. Some such list of institutions as e.g., school, church, public hall, library, post office, swimming bath, playing field, gymnasium, debating society, etc., are beginning to be recognized as essential and their provision attempted; but the recognition is not yet substantial. The desire for social organization is strong, but urban social development is still young and the inhabitants are in the experimental stage of working out what are the sort of institutions required to best meet the need of the citizens.

I. A paper read before the Sociological Society, November 25, 19r3. 
The third preliminary point is the absence of definite districts which will serve as natural foundations upon which to build social institutions or to which social institutions can be related. In their stead we find these institutions attached like barnacles to almost any existing foundation that can afford facilities, however meagre, for their organization. This, of course, is not the case with the new garden suburbs which form natural, self-contained districts in themselves. Ordinary suburbs on the outskirts also are more definite in character, because there is a certain expanse of unbuiltup land between suburb and suburb, or at any rate, between suburb and open country, and they have, therefore, distinct advantages as compared with those acres and acres of densely populated districts that one hurries through on the train en route.

\section{I.-The Haphazard Growth of District Social Institutions.}

The haphazard growth of the town is responsible for much of the tangle. Let us examine this a little. As soon as a house is erected it is put into a postal district. In Liverpool, for instance, no postal-district map of the town has ever been compiled, nor indeed could be. Postal districts consist of lists of streets which are allotted to various district offices, which lists are continually being added to. As a patch of fields becomes covered with houses new school accommodation is necessary, and the education authority secures a suitable site in relation, more or less, to its previously existing schools, and a new school is built. At the same time with a new growth of 1,000 or 2,000 houses a parish church finds added to it a congregation sufficient to fill it twice over (were it to attend). The ecclesiastical authorities, therefore, readjust areas and mark out a new daughter parish and, when they can, raise the funds to build a new church. Along the main road shops are erected and shopping thoroughfares formed. So a district comes into being and certain institutions are introduced. When the district is more or less fully built up, the land on the new outskirts is attacked and the same process repeated.

Gradually throughout this new large patch of streets societies are formed in connection with the various institutions which have arisen. Tradesmen in the shopping thoroughfare may form a football club. A group of young fellows travelling from the same local railway station or tram terminus may form a dramatic society. As the congregation gathers round the church or the various chapels which have also sprung up, athletic and social organizations are formed ; the new school develops a care committee, athletic teams, happy evenings and so forth. The individual in a district realises through notices of rates served on him and through voting lists posted about the place, that he is in one or other municipal 
ward of some urban district, and in time, perhaps, a ward political club is formed. A local branch of the Fabian Society is started. Some works are in the neighbourhood, and the firm starts a Welfare Secretary and organises athletic and social activities for some of their employees. Several women, as a result of various afternoon calls, ask a local organist to start a musical society or a glee party. By this haphazard method and after some considerable lapse of time if an area of a town be marked off with a ruler and examined, within it will be found the headquarters of a number of varied social institutions. The members attending these institutions will be drawn only partly from the area marked off. Many of them will come from outside. On the other hand the residents within the area will be found to belong to many institutions which are in the neighbourhood, but which are outside the area.

The haphazard method of the town's growth thus roughly outlined has certain important results which need to be borne in mind.

(I) The absence of any well-defined local district. A row of houses is added to the edge of a previous district, and at first the new inhabitants attach themselves to the old district. Then as the district becomes built up they find that they are much more closely allied to the new district which has just come into existence, or they may find themselves on a nebulous area with no particular claims on them to belong to any place or institution. The district itself loses its edges and boundaries, and becomes just a part of acres and acres of streets and houses-a vast indeterminate mass. The effect of this is that the residents possess no sense of locality or of relation to a locality. They do not live in a place with a claim, with a history, with a charm, with an appeal. Compare for a moment the inhabitant of Worcester or Todmorden with the inhabitant of 192 Bow Road, East; for large centres of population like London, Liverpool, Manchester, are not places at all, so far as the simple resident is concerned.

(2) There is an absence of any general common ground which will bring together all the residents as such. Periodically those who have the franchise are asked to select public representatives for Parliament or for the local authorities, but these they select through the conflict of party votes rather than by amity of common interests; and in voting they vote singly as individuals. Occasionally a town-hall meeting of citizens of the whole town is held, but on these occasions the simple citizen in a district or suburb rarely attends, nor would there be room for him were he to do so, indeed he may often never hear of such a gathering, unless perhaps through the report of a local paper. But the district as such never meets.

(3) The responsibility to the district on the part of the individuals 
is lost sight of. There is no machinery for bringing this responsibility home to the resident. The subject for responsibility is there, for the town's affairs are urgent and there are many things to be done. Also an inherent sense of responsibility exists in the individual. For lack of bringing the two together, however, the sense of personal responsibility dies.

(4) It rests with the individuals whether they belong to an institution or no. If they drift and belong to nothing, nothing happens. There is no general body in the district possessing the functions, on the one hand, of seeing that individuals have their interests satisfied and of encouraging their interests, and on the other of seeing that the necessary district institutions are brought into being and are co-ordinated.

(5) In a large town individuals tend to be lost sight of. This has two bad effects. There is less public incentive to an individual to keep himself steady, law-abiding and dignified. There is also less possibility of an individual's personal qualities being fully used. It is therefore necessary to make special efforts to counteract this tendency, by increasing the occasions on which the persons in the same district may meet each other, or at any rate by making use of any such occasions as already exist. This is not done because the institutions in a district are not confined to the resident of the district. As has already been mentioned, persons within the district belong to institutions outside the district, and persons from outside the district belong to institutions within the district. Persons in the same district, therefore, not only miss actual opportunities of making or deepening their acquaintance with fellow-residents, but instead use such opportunities to form quite unnecessary additional acquaintanceships with persons in other districts. This point is of considerable importance, and has not at present received the attention it deserves. It is a serious barrier to the development of fellowship and citizenship.

(6) A special district feature arises in the case of the absorbed village which by the invasion of the town loses its unity, its continuity of institutions and its peculiar character. Only by an extraordinary display of ability is such a village able to readjust itself and reorganise itself to meet the needs of its army of new citizens. Frequently the not unnatural cliquiness of the old residents renders the social organization of the newcomers more nebulous than ever.

(7) So far as the town as a whole is concerned, it suffers considerably from this haphazard district social life. The town does not form a related whole. The town's affairs are inadequately understood in the district; the town's appeal is indifferently heard; the sense of corporate responsibility to the town as a whole is practically non-existent; the need for social service meets with but 
a feeble response. The town becomes like a tree whose roots are thwarted from reaching the rich soil which awaits them and whose boughs produce in consequence but an enfeebled crop of fruit.

(8) The central institutions of a town are also affected in two interesting ways as individuals in the outlying districts join district institutions instead of central ones. Either the membership of the town's societies such, for instance, as its Literary and Philosophical Society, tend to be supported by a group of members neither representative of the town as a whole nor any particular district. They become, in fact, a district society without a district, weakening by this means the support of real district societies. Or they are supported by the leading and more well-to-do citizens, and thus become institutions of a particular class. The well-to-do and educated classes in a town form but a small proportion of the citizens, and the town exists as a single social unit for them much longer than it does for the simpler citizens. A further feature of importance is the ineffective way in which important new movements, e.g., branches of the W.E.A., when introduced in a town, fail to permeate its various districts.

\section{II.--'The Bases upon which District Social Institutions aRe FORMED.}

This haphazard method of growth and the indeterminate character of the district has led to the adoption of different bases for the formation of local social ${ }^{1}$ institutions. What are these?

(a) The Churches. The most widely adopted basis round which district social institutions are formed is the religious institution. Clergy and ministers are to be found in every locality throughout the country, and so far as the Church of England is concerned, every individual definitely lives within the jurisdiction (if such a term may be used) of a definite clergyman. When the democratic desire for social institutions began to express itself, the clergy and ministers conscious of its importance endeavoured to meet the need by grouping the new social organisations round their own religious institutions. In connection with these there have sprung up such activities as bands of hope, girls' friendly societies, boys' and girls' clubs, men's clubs, mothers' meetings, debating societies, athletic clubs, social evenings, etc., etc. Two points need to be noted with regard to this development. (i) This action is not confined by any means to the institutions of the Church of England. The religious institutions of all the religious bodies take part in it. (ii) Town churches draw their congregations largely from outside their parish boundaries, and as this practice is general, so far as social organisation

1. Social is here used in a narrower sense and excludes religious, educational, \&c., institutions. 
is concerned, parish boundaries can scarcely be said to exist. Further, probably in not a single case does the church provide all the necessary social institutions, and generally speaking it only provides one or two. There is very great variation in this matter. Thus one church may have a boys' club, another a debating society and a third neither, a fourth both, a fifth something quite different, etc.

In no case does a religious institution, however numerous its activities, cater for all its congregation. Thus, to quote a known instance, a well-organised church with a parish of ten thousand, had a number of social organisations running, but these embraced in all a membership of only some five hundred. Even assuming that a considerable proportion of the congregation were not in need of any particular social institution, there was a considerable shortage of provision which it was impossible for the church to supply. It must also be remembered that there are many individuals who are not attached to any of the religious institutions. For such, on this basis, there is no provision made.

(b) The Elementary Schools. These institutions touch only the school-age period of the individual's life (broadly from 5 to 14 ), but they are an institution through which practically all normal children pass and thus afford a valuable basis for social organisation. In addition to the elementary school system itself, which is very valuable, and the personal contact involved between scholar and teacher, the teachers have developed in many towns a general body of athletic effort. In addition, within recent years, there have sprung up in connection with the school, care committees, happy evening associations, and several other movements. The school is thus becoming increasingly a basis for the social organisation of child-life. The school caters for no particular area though in the main each school serves for a definite number of streets.

(c) The third basis is that of the large industrial works. These apply, of course, only to persons of working age, and the extent of their operation is comparatively small. The social institutions provided by such industrial enterprise are varied, consisting perhaps chiefly of athletics. The employees affected are by no means drawn from the same locality.

(d) The fourth basis is that of the little personal group of friends or acquaintances. They are attached to no definite institution though often hiring a room from some organisation for their meetings. This method is fairly common and is adopted frequently for the formation of dramatic societies, debating societies, musical societies and athletic clubs. It is also found, as might be expected, to flourish more extensively among those individuals who are able to pay for their organizations. In such organizations 
there is, of course, no question of local area at all. The basis of membership is comradeship in an individual group of persons, though probably the members all live, more or less, within the same locality.

(e) In a number of municipal wards, ward political clubs are formed by the various political parties, according to the organizing ability and funds of the respective parties. In order to render these groups more attractive, a social element is often introduced, such as a billiard table, social evenings, day outings, etc., etc. Some political clubs have undertaken (e.g., in Liverpool) to commence giving children's entertainments in their ward. The total number of persons affected by these organizations is comparatively small.

(f) The Friendly Society movement also provides a certain amount of social organization. Many of the friendly societies have their branch lodges in various parts of the town and have fortnightly meetings at which papers are read, musical evenings are given and there are occasional day outings.

$(g)$ There are the vague local societies. Sometimes a society formed by a group of friends is called by the name of the district and in a vague form it seems to be a local society. There is, for instance, in Liverpool the Wavertree Men's Society, which is a literary and debating society, or again the South Liverpool Parliamentary debating society. The extent of these is not very numerous.

This survey of the various bases of district social organizations reveals one or two important considerations.

(I) The first point to notice is that the total extent of social organization on all seven bases when added together does not nearly meet the need of the district. The only figures I have with regard to the actual extent of the shortage are taken from a survey in I9I I of one of the municipal wards in Liverpool (Netherfield Ward). This is, practically speaking, an industrial ward whose residents: are either artisan or labouring class. In one corner of the ward there is a considerable patch of slums. There are also a fair number of shopkeepers with a doctor or two and one or two clergy and ministers. With regard to the ward the following figures were obtained: Boys, school age (5 to 14) population 3,025; numbers. affected by social organizations, excluding attendance at day school and Sunday School, not more than 600; Girls, school period (5 to 14), population 3,223 ; number affected approximately 330 ; Boys, juvenile adult period ( 14 to 18 ) population 1,276 ; some 500 are affected; Girls, juvenile adult period (I4 to I8) population I,427; number affected 400; Adults ( 18 and upwards), males 9,825; number affected 800 , exclusive of the Territorials and members of thrift societies and trade unions; females, population 10,097; mothers' meetings 600, other agencies 150 . These figures may, I 
think, be taken as fairly average figures for an industrial neighbourhood. The shortage is considerable, even recognising that many persons would not, under perfect organization, join institutions.

(2) Secondly, there is the absence of any real district basis for organization. Of the above-mentioned forms three would seem to be possibly local, the Church of England parish, the municipal ward political club, and the local institution. Of these the last mentioned, the local institution, is local only in name and does not need serious attention. The political club is local and confined to the ward, but on the other hand, it is party and breaks the ward into three or more factions; also its degree of social organization is extremely slight. The other district basis to be considered is that of the ecclesiastical parish. This would seem to be at first sight a real district, but it is weakened as such, owing to the fact that in the town the parish church is congregational rather than parochial. Also the parish is a district only to members of the Church of England, but these do not form one third of the population.

The absence of this district basis of organization is a serious loss. Let me illustrate. A village, for instance, has its village institutions, its village school, its village hall, its village band, its village athletic clubs, all bearing upon the name of the village. There is thus ever present a village loyalty, a village spirit of comradeship, a village spirit of friendly rivalry with neighbouring villages. There is consequently within the village one single, uniting force towards the development of village loyalty and village fellowship. All the villagers have a common sentiment which acts as a bond between them. They may differ in politics, they may differ in creeds, they may differ in some of their social customs, but behind them all there is, for the many departments of life that are common to all, this common uniting force inspiring them to action. It is this force which, so far as district social organization is concerned, is absent in the town. It is this force, moreover, which must be introduced if the district's social organization is to be adequately undertaken and successfully carried out.

(3) Nor, again, are the institutions definitely related to the district. Children attending the same elementary school do not naturally attend the same church or chapel, swim in the same swimming bath, or pay in their savings at the same post-office. I am speaking generally, of course. Much less are all these institutions known by the same name-that of their district. Contrast this again with the village.

(4) The fourth point arises from the fact that social institutions are found attached to other institutions which exist for other purposes, e.g., religious, educational, political, etc. This has three results. 
First, social organization is treated as a lesser end and not a main end. Now, social organization is a main end, and should be treated as such. A valuable social force is thus lost. Secondly, the social institution is frequently used by the main institution to strengthen and support itself. This is bad. If the institution has not sufficient inherent vitality to live unsupported it should not be bolstered up. Further it is bad for the social institution to be thus attached to a decaying organization. There is yet a third difficulty in this matter. The institution most widely used as a basis round which to group social organizations is the religious institution. These are of different denominations and are thus essentially rival institutions. When social organizations are grouped round these rival religious institutions there is introduced a disintegrating force in social organization. Now the main feature of social organization is its uniting force. In social organization every piece of common ground or common sentiment is a potential link in drawing persons together. Yet in the above circumstance we find persons, for instance, with a common interest which, had it been given opportunity, would have drawn them together, sundered because in spite of these uniting bonds their organization for the encouragement of this common interest was an opposing force. There is also this added feature that in many cases forces oppose each other because they misunderstand each other. This opposition is prolonged because the first step to understanding, which could be made through the use of existing common interests, is unavailed of.

(5) The fifth point arises from the existence of option of choice as to the basis round which district social institutions should be grouped. Where the respective institutions used as bases are integral institutions of the ward and non-rivals, they ought not to be in rival opposition so far as their lesser object of social organization is concerned. On the contrary the social organization of the district should be so arranged that each integral institution mutually supports the others, if so far as their main objects are concerned they are needed. At the present time, in certain cases, we have rivalry. The most serious is that of the religious institution and the elementary school. Should the social organization with reference to the child of school age be based round the church or round the school? At present the child has on the one hand his school teacher urging loyalty to the school and the support of its athletic undertakings, on the other he has his religious teacher encouraging him or her to join a social institution at the church. This unsatisfactory attitude should yield to some understanding between the two institutions.

As has been pointed out, this apparent rival loyalty is only rival so far as the social organization is concerned. At present 
this rivalry does not create a serious difficulty because social organization is very incomplete, but as it becomes more complete the struggle will become quite acute, and it is important that in these earlier days some general plan should be settled which will prevent this unnecessary rivalry. The rival relation of the religious institution to the political ward club or to the Friendly Society is somewhat similar, except that the social organization is so slight in connection with the two latter that the matter is not very substantial. This is the case also with regard to social organization in connection with large industrial organizations. With regard to these, however, it is a question whether as social organization develops, their continuation will be advisable. Their existence weakens district social organization because it forces some of the active residents in the district, through loyalty to their firm's organization, to cut themselves adrift from the organizations of the district. Moreover, such a method of social organization at best, as stated earlier, is only partial, and can never be capable of general adoption, as it is only adaptable to a few business enterprises.

\section{III.-Suggested Unit of Social Organization.}

As will be gathered from the foregoing, there seems to be need for some general district unit-some locality which shall itself be the basis of certain social organization, and which shall also serve as the matrix for the various district institutions. The question then arises: What is the district which will serve as such a unit? This matter now needs our consideration. If a large town were to fall into natural, obvious, separate divisions easily distinguishable from one another and marked off by natural boundaries, such districts would obviously be the basis. This, however, is practically never the case. Occasionally, as has been mentioned before, on the outskirts of the town, Garden Suburbs are springing up which will serve, but these are only rare exceptions. The more one studies the plan of any single large town, the more impossible does it become for human ingenuity to puzzle out the miles and miles of solid streets and buildings into easily recognisable districts. Even were it to be done apparently satisfactorily, a study of these districts then marked out, would reveal that they were lacking in internal plan and arrangement. In the absence then of any natural divisions, the question arises, whether one should form new divisions by a study of the ground plan of the town, or whether one should adopt any of the divisions of the town already existing. What are these?

Towns are divided into districts in the main for four general objects. (a) For purposes of public administration, $(b)$ into ecclesiastical parishes, $(c)$ by various voluntary agencies for their special 
purposes, and $(d)$ there are the old local divisions. Something needs to be said about each of these.

(a) Public Administration.-The question of local areas for the purposes of public administration is intricate, and it is not within the scope of the present paper to go fully into the matter. The situation can only be briefly summarised and those points drawn out which bear upon the matter in hand. Towns are divided for public purposes in no fewer than six ways :-

(I) Into postal districts. This has already been alluded to above.

(2) Into Poor Law areas.

(3) Into Municipal Wards.

(4) Into Parliamentary constituencies.

(5) Into Police districts, and

(6) Into Registration districts.

Of these the postal district and the police district are alike in agreeing neither with each other nor with any of the other divisions. With regard to these other four-the Poor Law, the Municipal, the Parliamentary and the Registration districts-they can all be expressed in terms of Municipal Wards, with very occasional exceptions. The municipal ward is, therefore, nearly always, and its polling districts always, definitely in one or other of these four divisions. Much confusion, however, exists with regard to local administration units, for two reasons. Partly because they are divided up in six ways instead of one, and partly because the nomenclature of the various districts thus created is so confusing. The same name may be used for a municipal ward, for a postal district, for a police district, for a parliamentary constituency, for a poor-law parish, and in each case the name means quite a different area. Some of the districts may be even quite outside any of the others. This is very confusing, and a person living in one of these districts has, therefore, not the slightest idea where he lives or to what he belongs. The name is meaningless. Contrast this once more with all that the name of a village implies.

(b) The Ecclesiastical Parishes.-This division has been already alluded to, but the following points about it need to be taken into account. It is not more obvious in its character than the wards or any of the other divisions. It only concerns the Church of England, and the Church of England does not constitute one third of the population. As mentioned earlier churches in towns tend to become congregational and disregard their parishes.

(c) Divisions by Voluntary Agencies.-The town is divided up by voluntary agencies for a variety of purposes, perhaps the most important being the divisions of the Charity Organisation Society or the Guild of Help, and the Queen Victoria District Nursing Association. The division by charitable bodies is done on no 
general plan, but in each case to suit the particular needs of the Society. Their divisions therefore do not help much in a consideration of the matter, except with regard to that of the Guild of Help. In Manchester, which is one of the best organised Guilds of Help, and in one or two other towns, the municipal ward is adopted as the unit, and when it is necessary to subdivide them, the polling districts are taken.

(d) The Old Local Divisions.- -Some different parts of the town have attached to them old local names arising from the fact that there were the villages which have since been absorbed by the growth of the town. The name lingers on, but the boundaries are quite indeterminate. These old place names have also been in nearly all cases adopted as names of one or other of the areas for public administration, and they add to the general confusion already mentioned.

From this survey of the existing district divisions, the most generally used seems to be that of the municipal ward. It now only remains to discuss how far this is possible to be adopted as the district unit for social organization.

\section{IV.-The Municipal Ward as the District Unit for Social ORGANIZATION.}

In considering how far a ward is the suitable district unit the following points come up for consideration.

(1) The Size of the Ward. What is the most suitable number of people which could be grouped for a single social unit? The most convenient size of the unit varies with the particular need of social organization. Thus, for instance, an average town church holds about 700 people, and supposing that one in ten come to church, such accommodation would provide for a district of 7,000 . On the other hand with a population of this size there would be about 250 boys between the ages of 14 and 18 , and even supposing half of these did not play, it would not be possible to get all the others into, e.g., a single football team.

The only feasible course is to take a suitable unit for general purposes, duplicating institutions in some cases and sharing a joint institution with a group of wards in others; in some cases one institution would do for the whole town, e.g., geological society. An ideal size for the unit would probably be from 5,00o to 10,0oo. The size of a municipal ward varies considerably, $e . g .$, in Liverpool from 2,000 to 40,000. The average population of a Liverpool ward being about 20,000. In large towns the unit of the district will probably need to be larger than in smaller towns because the relation of the district unit to the town as a whole must be taken into account. There are, for instance, in Liverpool thirty-four wards. It would probably be better to organize thirty-four wards 
of 20,000 people than sixty-eight wards of 10,000 . We need a series of experiments to work out the ideal size for a social unit; and the varying size and character of the wards would thus furnish a useful variation in experimenting.

(2) The second point is the relation of the particular institution to the ward. It will not be possible, even were it desirable, at any rate for some years, to ignore the institution as a basis of organization. The change of basis from that of the institution to that of the locality will be slow, and can only take place as the sense of locality ripens. An immediate step which might be taken at any time is the relating of the institutions in the ward to the ward. The institutions should be considered as integral parts of the ward's organization and should stand in a mutual relation to each other.

With some institutions there would not be much difficulty, e.g., Friendly Societies. The difficulties would probably be in relating (a) the churches, $(b)$ the schools, to the ward. In both these cases the institutions are not movable and may be situated on the verge of a ward, drawing their clientèle, therefore, in the main from a neighbouring ward. In such cases the institutions would probably be placed in the ward in which they were situated and at first membership of the institution would involve membership of the ward. Gradually, however, as the ward idea became realised, these border cases would tend to diminish; a little more easily, perhaps, in the case of schools than churches, but in the latter case only the church's social institutions need to be considered. In Liverpool Roman Catholics have an interesting plan of filling the houses next their churches with Catholics; opportunity being taken of filling empty houses as they occur.

In such relating the name of the ward might play a proper part. For instance the elementary school in a ward might be known by the name of the ward. The child attending the school will thus become conscious that it is not only a member of the school but it is a member of the ward. The child attending school, moreover, will, once the ward institutions are related, be aware of the political institutions in the ward when its inclinations turn that way; it will be aware too, of the religious institutions in the ward; it will also be aware of the new organizations for juvenile adults, and thus on leaving school it will know already the particular institution in the ward which it will naturally join.

(3) The ward would need to develop its sense of locality. At present its boundaries are not obvious and are artificial. It is impossible to tell as one walks along the street where one ward ends and where the next begins. It will be necessary to render these boundaries as obvious as possible. For instance, the old practice of beating the bounds might be revived; some system might be adopted of painting the lamp-posts in the wards a 
different colour, and marking quite obviously the ward boundaries on the walls of the houses where the dividing lines occur, etc. It would also be possible in time, as the ward idea develops, to alter the existing boundaries of the wards, to readjust them gradually where obvious inconveniences exist, using where possible natural boundaries such as railway lines, open spaces, etc., as boundaries. The Local Government Board has power to authorise this.

(4) Fourthly, there would be needed a general organization in the ward to promote its social welfare-something broadly on the lines of the representative Tenants' Council of the garden suburbs. This body would be generally responsible for seeing that in one way or another the various social institutions necessary in a ward were provided. This body would also summon ward meetings in matters of public interest. Such a body might also undertake the personal visitation of all newcomers to the ward, the idea being that every newcomer to the ward is a citizen of that ward and should be definitely welcomed as such. This body would also possibly undertake the friendly visiting of persons in difficulty or distress, etc. It is of interest to note that bodies of this kind are already being formed, e.g., at the Wavertree Garden Suburb Tenants' Representative Council; at Hightown, etc.

The ward would also be the local centre when generally organizing a movement in the town. The W.E.A., for instance, might have its local ward committee to work up matters in each particular ward. The organization, too, of good musical concerts could be done on this basis, there being a general body in the town and local committees in each ward for the organization of the district concerts and so on. One need not go into detail upon the matter, but it is clear that some general body in the ward is necessary for two broad purposes, the internal organization of the institutions of the ward, and for organizing the district effort in relation to the town as a whole.

These considerations seem to indicate that there are no essential difficulties to the adoption of the ward as a basis of social organization and that it appears on the whole the most suitable basis. I may perhaps add in conclusion that I have laid these proposals and suggestions before a series of audiences in Liverpool, e.g., Adult School Members, Workers' Educational Association, District Teachers' Association, Men's Societies in connection with churches, Women's Co-operative Guild, etc., etc. On every occasion members of the audience have come up afterwards to express their sense of the need for and the value of some such development. 